\title{
Air-sea dimethylsulfide (DMS) gas transfer in the North Atlantic: evidence for limited interfacial gas exchange at high wind speed
}

\author{
T. G. Bell ${ }^{1, *}$, W. De Bruyn ${ }^{2}$, S. D. Miller ${ }^{3}$, B. Ward ${ }^{4}$, K. Christensen ${ }^{5}$, and E. S. Saltzman ${ }^{1}$ \\ ${ }^{1}$ Department of Earth System Science, University of California, Irvine, CA, USA \\ ${ }^{2}$ Department of Physical Sciences, Chapman University, Orange, California, CA, USA \\ ${ }^{3}$ Atmospheric Sciences Research Center, State University of New York at Albany, NY, USA \\ ${ }^{4}$ School of Physics, National University of Ireland, Galway, Ireland \\ ${ }^{5}$ Norwegian Meteorological Institute, Postboks 43, Blindern, 0313 Oslo, Norway \\ * now at: Plymouth Marine Laboratory, Prospect Place, The Hoe, Plymouth, PL1 3DH, UK
}

Correspondence to: T. G. Bell (tbe@pml.ac.uk)

Received: 29 March 2013 - Published in Atmos. Chem. Phys. Discuss.: 21 May 2013

Revised: 9 October 2013 - Accepted: 11 October 2013 - Published: 13 November 2013

\begin{abstract}
Shipboard measurements of eddy covariance dimethylsulfide (DMS) air-sea fluxes and seawater concentration were carried out in the North Atlantic bloom region in June/July 2011. Gas transfer coefficients $\left(k_{660}\right)$ show a linear dependence on mean horizontal wind speed at wind speeds up to $11 \mathrm{~m} \mathrm{~s}^{-1}$. At higher wind speeds the relationship between $k_{660}$ and wind speed weakens. At high winds, measured DMS fluxes were lower than predicted based on the linear relationship between wind speed and interfacial stress extrapolated from low to intermediate wind speeds. In contrast, the transfer coefficient for sensible heat did not exhibit this effect. The apparent suppression of air-sea gas flux at higher wind speeds appears to be related to sea state, as determined from shipboard wave measurements. These observations are consistent with the idea that long waves suppress near-surface water-side turbulence, and decrease interfacial gas transfer. This effect may be more easily observed for DMS than for less soluble gases, such as $\mathrm{CO}_{2}$, because the air-sea exchange of DMS is controlled by interfacial rather than bubble-mediated gas transfer under high wind speed conditions.
\end{abstract}

\section{Introduction}

Gas exchange between the ocean and atmosphere is a major term in the global budgets of many compounds with biogeochemical and climatic importance. For example, air- sea gas exchange controls the oceanic uptake and/or release of carbon dioxide, oxygen, nitrous oxide, methane, halocarbons, dimethylsulfide (DMS) and ammonia, and the cycling of volatile toxic pollutants such as mercury and many pesticides (Butler et al., 2010; Stramma et al., 2008; Bange et al., 2009; Lana et al., 2011; Johnson et al., 2008; Sabine et al., 2004; Soerensen et al., 2010; Harman-Fetcho et al., 2000). Parameterization of air-sea gas transfer is one of the major uncertainties in global biogeochemical models (e.g. Elliott, 2009). A better understanding of gas transfer rates and their controlling factors is needed in order to predict how air-sea gas fluxes will vary in the future in response to changing climate and anthropogenic emissions.

The air-sea flux of gas is proportional to the concentration difference across the interface $(\Delta C)$ and a gas transfer coefficient, $K$, expressed in water-side units: $K_{\mathrm{w}}$ (Liss and Slater, 1974):

$F_{\mathrm{DMS}}=K_{\mathrm{w}} \cdot \Delta C$.

$K_{\mathrm{W}}$ includes the combined effect of diffusive and turbulent processes on both sides of the interface that limit the transfer of gas between the bulk seawater and air phases. The physical forcing for gas transfer is wind stress and buoyancy at the sea surface. Whitecaps/bubble production, wind-wave interactions and surface films all play a role in determining the rate of gas transfer (Wanninkhof et al., 2009).

Estimates of oceanic gas transfer coefficients and their dependence on wind speed, diffusivity, and solubility have 
been derived from the global oceanic inventory of excess radiocarbon, laboratory wind-wave experiments, and dual tracer experiments with ${ }^{3} \mathrm{He}$ and $\mathrm{SF}_{6}$ (e.g. Ocampo-Torres et al., 1994; Watson et al., 1991; Sweeney et al., 2007; Liss and Merlivat, 1986; Wanninkhof, 1992; Wanninkhof and McGillis, 1999; Nightingale et al., 2000; Ho et al., 2006; Broecker et al., 1985; Wanninkhof et al., 2009). A number of physical process-based models have been developed to estimate air-sea gas transfer rates. These include the effects of turbulent transport, buoyancy, bubbles, Langmuir circulation and wind-wave interactions (e.g. Fairall et al., 1996, 2011; Hare et al., 2004; Johnson, 2010; Rutgersson et al., 2011; Soloviev et al., 2007; Soloviev, 2007).

Gas solubility exerts a significant influence on air-sea exchange. Gas transfer rates are controlled by transport on the seawater side of the interface for relatively insoluble gases like $\mathrm{CO}_{2}$. More soluble gases, like acetone, are controlled primarily by transport on the atmospheric side of the interface. Solubility also determines the extent to which whitecaps and bubbles contribute to gas transfer (Woolf, 1997). For example, bubbles are believed to dominate the gas transfer for $\mathrm{CO}_{2}$ at high wind speeds, while they are a relatively minor component of the flux for DMS.

The influence of wind-wave interactions on gas transfer is an understudied aspect of air-sea gas exchange. There is evidence that waves can influence near-surface turbulence (Schnieders et al., 2013; Savelyev et al., 2012) and that the presence of swell may modify the roughness of wind seas (García-Nava et al., 2009, 2012). Laboratory studies have demonstrated that flow separation at wave crests can create a shielding effect on the lee side of the wave, and reduce the friction velocity at the surface (Veron et al., 2007; Reul et al., 1999, 2008). Some models have attempted to incorporate the effect of waves into the estimate of gas transfer (Soloviev et al., 2007; Soloviev, 2007; Soloviev and Schlussel, 1994), but it has not been observed directly in the field (Nightingale et al., 2000; Smith et al., 2011).

Micrometeorological techniques involve the direct determination of air-sea gas fluxes on the atmospheric side of the interface. Eddy covariance measurements have been made at sea for $\mathrm{CO}_{2}$ (e.g. McGillis et al., 2001, 2004; Miller et al., 2010) and for DMS (Huebert et al., 2004; Marandino et al., 2007, 2008, 2009; Blomquist et al., 2006; Yang et al., 2011; Huebert et al., 2010). Micrometeorological techniques have the potential to measure gas transfer rates on shorter timescales than the integrative geochemical or surface ocean budget techniques, providing the opportunity to study the response of the sea surface to local changes in wind and wave fields. The difference in solubility between DMS and $\mathrm{CO}_{2}$ offers the potential to differentiate between interfacial and bubble-mediated gas transfer (Blomquist et al., 2006).

This paper presents eddy covariance measurements of air-sea DMS flux on a June/July 2011 cruise aboard the R/V Knorr in the North Atlantic Ocean (Knorr_11). The cruise started and ended at Woods Hole, Massachusetts, USA

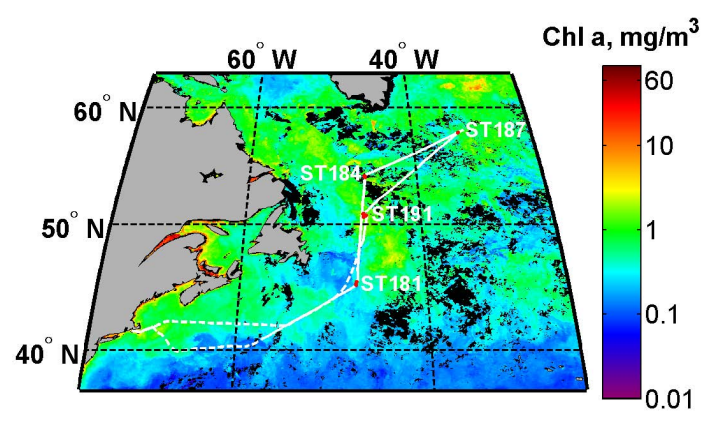

Fig. 1. Cruise track from the Knorr_11 study, with the location of stations marked in red. The cruise track is superimposed on a satellite map of chlorophyll $a$ from MODIS.

$\left(41.53^{\circ} \mathrm{N}, 70.68^{\circ} \mathrm{W}\right.$; Fig. 1), and roughly half of the cruise was spent in the high-productivity, high-latitude waters of the North Atlantic bloom. This study was designed to increase the observational database for gas transfer in a region of the oceans where biological activity results in exceptionally large air-sea DMS and $\mathrm{CO}_{2}$ fluxes. This study also represented an opportunity to revisit a region where an earlier study observed anomalously high DMS gas transfer coefficients inconsistent with current models (Marandino et al., 2008).

\section{Methods}

\subsection{Mast-mounted instrumentation and data acquisition setup}

The eddy covariance setup was mounted on the Knorr bow mast at a height of $13.6 \mathrm{~m}$ above the sea surface. This included two sonic anemometers (Campbell CSAT3), measuring 3-dimensional winds and sonic temperature, and two Systron Donner Motion Pak II (MPII) units measuring platform angular rates and accelerations. Air sampling inlets for DMS, consisting of $3 / 8^{\prime \prime}$ ID Teflon tubes, were mounted $0.2 \mathrm{~m}$ from the sensing region of the anemometers at the same height. Analog signals from the anemometers, motion sensors, and mass spectrometer were filtered using Butterworth filters ( $15 \mathrm{~Hz}$ cutoff frequency) and logged at $50 \mathrm{~Hz}$ using a multichannel data acquisition system (National Instruments SCXI-1143) and custom Labview ${ }^{\mathrm{TM}}$ software. Data from the ship's compass and GPS systems were logged digitally at $1 \mathrm{~Hz}$.

\subsection{Atmospheric DMS}

Atmospheric DMS levels were measured using an atmospheric pressure chemical ionization mass spectrometer (API-CIMS). DMS detection involved proton transfer from $\mathrm{H}_{3} \mathrm{O}^{+}$to DMS in the gas phase, followed by quadrupole mass filtering and ion counting detection of protonated DMS 
(Marandino et al., 2007; Blomquist et al., 2010; Bandy et al., 2002). A new instrument was used in this study (UCI mesoCIMS), consisting of a heated ion source $\left(400^{\circ} \mathrm{C}\right.$, operated at 550 Torr), a declustering region ( 0.5 Torr), and differentially pumped quadrupole entry and ion detection chambers. A full description of the instrument is provided in the Supplement.

The mesoCIMS was located in a container van on the Knorr 02 deck, one level above the main deck. Air was drawn from the bow mast inlet to the instrument van through a $28 \mathrm{~m}$ length of $3 / 8^{\prime \prime}$ ID Teflon tubing at a flow rate of $80 \mathrm{~L} \mathrm{~min}^{-1}$. These conditions provided fully turbulent flow $(R e>10000)$. The air flow rate was maintained by a rotary vane pump, with active control provided by a mass flow meter, automated butterfly valve, and PID controller. An air flow of $1 \mathrm{~L} \mathrm{~min}^{-1}$ was drawn off the main inlet flow through a Nafion ${ }^{\mathrm{TM}}$ membrane drier and through the mass spectrometer ion source. This air flow was controlled by a mass flow controller and diaphragm pump.

Standardization of DMS measurements was accomplished by introducing a tri-deuterated DMS gas standard (d3-DMS) into the main air flow a few $\mathrm{cm}$ downstream of the air intake. The preparation and delivery of DMS gas standards is described in the Supplement. Protonated DMS $(m / z=63)$ and d3-DMS $(m / z=66)$ were continuously monitored in selected ion mode with a $45 \mathrm{~ms}$ dwell time and a delay of $5 \mathrm{~ms}$. The sensitivity of the instrument to DMS during the cruise was approximately $100 \mathrm{~Hz} \mathrm{ppt}^{-1}$, as estimated from the response to the d3-DMS standards. Every two hours, a 3-way valve mounted on the bow mast diverted the flow of gas standard to waste. The response of the d3-DMS signal to this event provides a measure of the delay and frequency response loss associated with the inlet tubing.

Atmospheric DMS levels were calculated as follows:

$\mathrm{DMS}_{\mathrm{a}}=\frac{S_{63}}{S_{66}} \cdot \frac{F_{\text {Std }}}{F_{\text {Total }}} \cdot C_{\text {Tank }}$,

where $S_{63}$ and $S_{66}$ represent blank-corrected signals from DMS and d3-DMS, respectively $(\mathrm{Hz}) ; F_{\text {Std }}$ and $F_{\text {Total }}$ are the gas flow rates of the d3-DMS standard and the inlet air $\left(\mathrm{L} \mathrm{min}^{-1}\right)$; and $C_{\text {Tank }}$ is the gas standard mixing ratio. The raw d3-DMS signal was averaged over each 10 min flux interval to remove variability caused by motion sensitivity of the mass flow controller used to supply the gas standard on this cruise.

\subsection{Seawater DMS}

DMS in seawater was continuously monitored using a second API-CIMS instrument (UCI miniCIMS) and a porous membrane equilibrator. Details of the construction and performance of the mass spectrometer and equilibrator are given in Saltzman et al. (2009) and are only briefly described here. The miniCIMS ion source chemistry and principles of detection are similar to those described earlier. This instrument uses quadrupole and ion detection electronics from a modified residual gas analyzer (Stanford Research Systems RGA200). It is less sensitive than the mesoCIMS, but adequate to detect DMS over the range of concentrations encountered in the surface of the open ocean.

The equilibrator construction consists of a coiled outer PFA tube $\left(8 \mathrm{~m} \times 3 / 8^{\prime \prime}\right.$ ID) and a porous inner concentric PTFE membrane inner tube ( $3 \mathrm{~mm}$ ID, $60-70 \%$ porosity; International Polymer Engineering). Surface seawater was supplied by the ship's non-toxic bow pumping system, with an intake depth of $6 \mathrm{~m}$. A seawater flow of approximately $1 \mathrm{~L} \mathrm{~min}^{-1}$ was supplied to the equilibrator. The seawater flow rate was monitored using a GEMS flow meter (Gems Sensors \& Controls; P/N 155421). A purified air counterflow of $400 \mathrm{~mL} \mathrm{~min}^{-1}$ flowed through the inner membrane tube (Aadco Instruments Pure Air Generator). The air exiting the equilibrator was diluted with purified air to give a total flow of $1.5 \mathrm{~L} \mathrm{~min}^{-1}$ of purified air, passed through a Nafion membrane drier (Perma Pure MD-110-72FP) and directed through the ion source. The ion source in this instrument was operated at 1 atmosphere. All gas flows were mass flow controlled and logged. In high wind conditions, a debubbling reservoir was inserted in the seawater flow and a peristaltic pump was used to deliver bubble-free seawater to the equilibrator. The quantity of air in the seawater line was never sufficient to significantly bias seawater DMS levels.

The seawater measurements were calibrated by continuously adding isotopically labeled aqueous d3-DMS standard to the seawater flow prior to entering the equilibrator. A working standard of $0.13 \mathrm{mM}$ d3-DMS was delivered at a flow rate of $30 \mu \mathrm{L} \mathrm{min}^{-1}$ using a syringe pump (New-Era NE300). The working standard was prepared daily by dilution of a primary standard $(43 \mathrm{mM} \mathrm{d} 3-\mathrm{DMS}$ in ethanol, prepared prior to the cruise) with deionized water.

The DMS concentration in seawater in the equilibrator is calculated as follows:

$\mathrm{DMS}_{\mathrm{SW}}=\frac{S_{63}}{S_{66}} \cdot \frac{F_{\mathrm{Std}}}{F_{\mathrm{SW}}} \cdot C_{\mathrm{Std}}$.

$S_{63}$ and $S_{66}$ represent the average blank-corrected ion currents $(\mathrm{pA})$ of protonated DMS $(m / z=63)$ and $\mathrm{d} 3-\mathrm{DMS}$ $(m / z=66)$, respectively; $C_{\text {Std }}$ is the concentration of d3DMS liquid standard (nM); $F_{\text {Std }}$ is the syringe pump flow rate $\left(\mathrm{L} \mathrm{min}{ }^{-1}\right)$; and $F_{\mathrm{SW}}$ is the seawater flow rate $\left(\mathrm{L} \mathrm{min}^{-1}\right)$. Seawater concentrations were averaged at $5 \mathrm{~min}$ intervals.

Prior deployments of the miniCIMS utilized a gas standard added to the air stream as it exited the equilibrator (Saltzman et al., 2009). This approach requires complete equilibration across the membrane, which requires some effort to quantitatively validate during cruise conditions. The use of liquid standards was prompted by concern regarding the possible loss of gas exchange efficiency of the equilibrator membrane due to fouling by gelatinous material encountered during passage through phytoplankton blooms. Although apparently rare, this effect was observed during a recent cruise in the 
South Pacific (S. J. Royer, personal communication, 2011). In that case, the membrane was completely blocked and required cleaning with strong acid to restore gas exchange. The use of a liquid standard eliminates the requirement for complete equilibration, since both the natural DMS and the d3DMS standard are transported across the membrane.

Underway lines can become contaminated with algal/bacterial mats, which can alter the concentrations of various biogeochemically produced compounds (Juranek et al., 2010). To address this issue we periodically placed an underwater pump over the side of the ship and made nearsurface measurements. DMS concentrations from the underwater pump at $5 \mathrm{~m}$ (Fig. 2c, pink squares) compared well with those from the vessel's non-toxic supply (Fig. 2c, green circles). These comparisons show that the ship's seawater line was not significantly influenced by biological growth.

\subsection{DMS flux calculation (eddy covariance data processing and quality control)}

The calculation of DMS air-sea flux from the shipboard measurements involved the following steps: (1) correction of the measured apparent winds for ship orientation and motion; (2) adjustment of the relative timing of wind and DMS measurements to correct for delay in the inlet tubing; (3) computation of the DMS flux, $\left\langle w^{\prime} c^{\prime}\right\rangle$; (4) identification of intervals with excessive flux at low frequency; and (5) correction for flux loss due to attenuation of high-frequency fluctuations in the inlet tubing. Momentum and heat fluxes were also computed.

The measured winds were corrected for ship motion using 3-dimensional accelerations and angular rates from the MotionPak II, GPS and compass. The measured winds are rotated into the ship frame of reference, resulting in zero mean vertical wind and a single horizontal wind vector. These relative winds are then transformed into an Earth frame of reference. Details of the motion correction procedure are given by Edson et al. (1998) and Miller et al. (2008).

The $28 \mathrm{~m}$ inlet tubing introduced a delay of about $2.2 \mathrm{~s}$ between the wind signal and the DMS signal. This delay was estimated by periodically cycling the 3-way valve delivering d3-DMS to the inlet and recording the time delay between the voltage driving the valve and the resulting change in DMS signal. A similar estimate of the delay was obtained by optimizing the cross correlation between DMS and vertical wind. DMS fluxes were calculated for 10 min flux intervals by integrating the frequency-weighted cospectral density of DMS and vertical wind. No corrections were made for fluctuations in air density due to changes in water vapor or temperature (i.e. Webb et al., 1980) because the air stream was dried, passed through a considerable length of tubing, and heated prior to analysis (Marandino et al., 2007). The internal d3DMS standard exhibited negligible covariance with vertical wind, confirming that no density correction is required.

Flux intervals exhibiting excessive flux (either positive or negative) at low frequencies were flagged and eliminated from the data set. These can result from changing environmental conditions, such as the passage of atmospheric fronts, changes in wind direction, transects across oceanographic fronts, etc., and presumably do not reflect the local air-sea flux. These intervals were identified by examining the cumulative sum (low to high frequency) of normalized flux $\left(F_{\text {sum }} / F_{\mathrm{DMS}}\right)$ as a function of $f_{\text {norm }}\left(f \cdot z / U_{10 n}\right)$, where $f$ is frequency $(\mathrm{Hz}), z$ is the measurement height, and $U_{10 n}$ is mean wind speed at $10 \mathrm{~m}$ height and for neutral conditions. The criteria for elimination are outlined in the Supplement. This process removed 461 of the 1437 flux intervals. This treatment resulted in reduced scatter in the data but did not introduce an obvious bias.

The distortion of air flow over the research vessel is a source of uncertainty in eddy covariance measurements. Flow distortion is believed to have a relatively small effect on scalar fluxes (Pedreros et al., 2003). To minimize the impact of flow distortion, shipboard eddy covariance studies typically use relative wind sector as a quality control criterion. Following careful analysis of Knorr_11 wind sector data (see Supplement) flux intervals with a mean relative wind direction $>|90|$ were excluded.

Diffusion of DMS during passage through the inlet tubing caused attenuation of fluctuations in the mixing ratio at the detector relative to those in ambient air (Massman, 2000; Lenschow and Raupach, 1991). This effect is quite small at the high air flow rates used in this study. The process was modelled as a low-pass first-order Butterworth filter, with a time constant adjusted to match the response of the DMS signal to a step change in d3-DMS at the inlet induced by switching the 3-way valve. This filter was applied in an inverse mode to the DMS signal. Flux- and frequencynormalized DMS cospectra were bin-averaged into $2 \mathrm{~m} \mathrm{~s}^{-1}$ wind speed bins. Binned cospectra were inverse-filtered to give an estimate of the high-frequency flux signal lost in the tubing. A "gain" $\left(G_{\mathrm{hf}}\right)$ was then computed from the ratio of these fluxes. $G_{\mathrm{hf}}$ was computed for flux frequencies $<1 \mathrm{~Hz}$ to avoid the amplification of noise (Blomquist et al., 2010). $G_{\mathrm{hf}}$ displayed a small linear dependence on mean wind speed $\left(G_{\mathrm{hf}}=1.0079+0.0008 \cdot U_{10 n}\right)$. This wind-dependent correction was applied to the data based on the mean wind speed for each flux interval.

\subsection{DMS gas transfer velocity calculation}

Total gas transfer velocities were calculated from the cruise data using the equation

$K_{\mathrm{DMS}}=\frac{F_{\mathrm{DMS}}}{\Delta C}=\frac{F_{\mathrm{DMS}}}{\mathrm{DMS}_{\mathrm{sw}}-\mathrm{DMS}_{\mathrm{air}} \cdot H_{\mathrm{DMS}}}$,

where $F_{\mathrm{DMS}}$ is the measured DMS air-sea flux $\left(\mathrm{mol} \mathrm{m}^{-2} \mathrm{~s}^{-1}\right), \mathrm{DMS}_{\mathrm{sw}}$ is the seawater DMS level (mol $\left.\mathrm{m}^{-3}\right), \mathrm{DMS}_{\text {air }}$ is the atmospheric DMS partial pressure (atm), and $H_{\text {DMS }}$ is the temperature-dependent DMS solubility in seawater $\left(\mathrm{mol} \mathrm{atm}^{-1} \mathrm{~m}^{-3}\right.$; Dacey et al., 1984). 


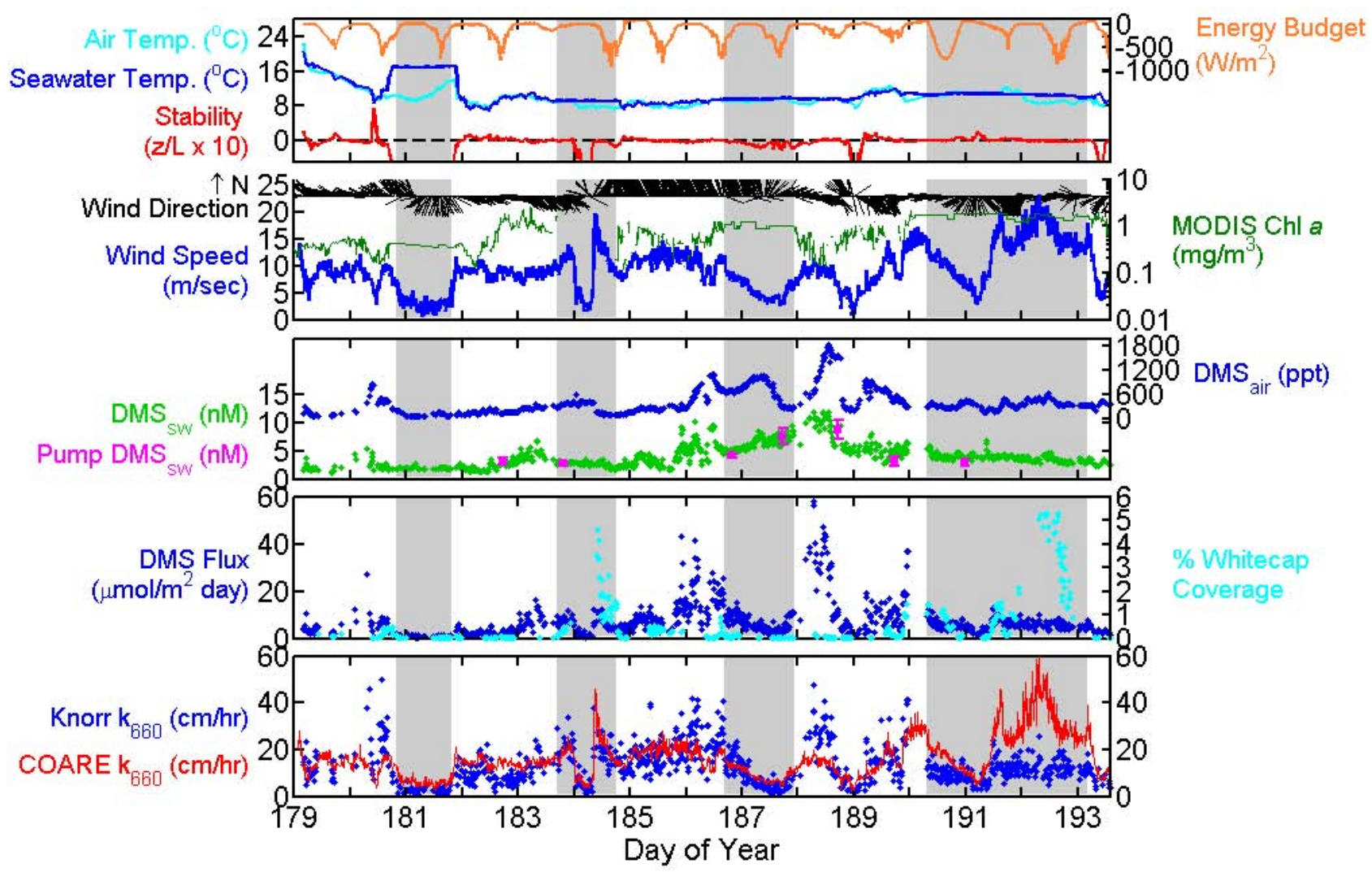

Fig. 2. Time series data from the Knorr_11 cruise. Dashed black line on top panel indicates neutral atmospheric stability $(z / L=0)$. Submersible pump $\mathrm{DMS}_{\mathrm{sw}}$ error bars are $\pm 1 \sigma$.

$K_{\mathrm{DMS}}$ values were calculated from the cruise data using 10 min averages of $\mathrm{DMS}_{\mathrm{air}}, \mathrm{DMS}_{\mathrm{sw}}$, and $H_{\mathrm{DMS}}$, and the 10 min flux calculations described above.

The total gas transfer velocity of DMS ( $\left.K_{\mathrm{DMS}}\right)$ reflects the combined effect of processes at both the air and water sides of the air-sea interface. The relative importance of air- vs. water-side resistance varies as a function of wind speed and solubility (McGillis et al., 2000). Our Knorr_11 cruise observations were used in conjunction with the NOAA COARE gas transfer model (version 3.1v) to estimate the air-side gas transfer coefficient for DMS associated with each of the airsea flux measurements (Fairall et al., 2011). The water-sideonly gas transfer coefficient, $k_{\mathrm{w}}$, was then obtained from the expression

$k_{\mathrm{w}}=\left[\frac{1}{K_{\mathrm{DMS}}}-\frac{1}{\alpha \cdot k_{\mathrm{a}}}\right]^{-1}$

where $K_{\mathrm{DMS}}$ is the total DMS gas transfer coefficient, $\alpha$ is the dimensionless Henry's Law constant for DMS, and $k_{\mathrm{a}}$ is the air-side gas transfer coefficient obtained from NOAA COARE. The average (mean) difference between $k_{\mathrm{w}}$ and $K_{\text {DMS }}$ was $6 \%$. To facilitate comparison of these results with various gas transfer parameterizations, $k_{\mathrm{w}}$ was normalized to a Schmidt number of $660\left(\mathrm{CO}_{2}\right.$ at $\left.25^{\circ} \mathrm{C}\right)$ : $k_{660}=k_{\mathrm{w}} \cdot\left(\frac{660}{S c_{\mathrm{DMS}}}\right)^{-1 / 2}$,

where $S c_{\text {DMS }}$ is calculated according to Saltzman et al. (1993) using the in situ seawater temperature recorded at the bow of the ship.

\subsection{Surface wave measurements}

Wave measurements were conducted using a $75 \mathrm{kHz}$ ultrasonic sensor (U-GAGE QT50U, Banner Engineering) in combination with a $\pm 20 \mathrm{~m} \mathrm{~s}^{-2}$ two-axis linear accelerometer (DE-ACCM2G2, Dimension Engineering). The ultrasonic sensor was mounted at the end of a steel pole, which was suspended vertically through the hawsehole at the bow of the ship, and then bolted to a mount that had been welded to the ship. The accelerometers were attached to the top of the steel pole, and were aligned to measure pitch and roll. Analog outputs of the ultrasonic sensor and accelerometer were logged at $100 \mathrm{~Hz}$.

The ultrasonic sensor was programmed for a range of $8 \mathrm{~m}$ and an update rate of $10 \mathrm{~Hz}$. Ultrasound pulses were emitted and the time lag of the echo recorded. The distance to 
the undulating surface was determined using the speed of sound with compensation for changes in air temperature. Ship motion was removed using the acceleration data, and the residual signal represents a time series of sea surface elevation. These data were bandpass-filtered between 0.05 and $0.5 \mathrm{~Hz}$. One-dimensional surface wave spectra were produced in $30 \mathrm{~min}$ averages. This method was compared to data from a commercially available waverider (Datawell Directional Waverider Mk III) during an experiment in Norway, and yielded good agreement (Christensen et al., 2012). For the data set here, a comparison was made with the output from the ECMWF Wave Model (WAM), with 6-hourly output and $0.1^{\circ}$ horizontal resolution. The shipboard wave sensor data contain more variability (more consistent with changes in measured local winds), but on average agree well (within $10 \%$ ) with WAM with respect to significant wave height and mean and peak periods.

\subsection{Whitecaps}

Whitecap areal coverage was measured using a digital camera (CC5MPX, Campbell Scientific) trained on the sea surface to collect images at a sample period of about $1 \mathrm{~s}$. The camera is housed in an enclosure with a fan/heater to control condensation. Images were post-processed to calculate the whitecap fraction of the sea surface, following Callaghan and White (2009).

\section{Results}

\subsection{Cruise track, meteorological, and oceanographic setting}

The cruise track for this study was north from Woods Hole, MA, through the Gulf Stream and northwest Atlantic shelf into the high-latitude North Atlantic (Fig. 1). The ship returned to Woods Hole via North Atlantic Drift and northwest Atlantic shelf waters. The cruise was carried out in early-mid-summer from 24 June to 18 July 2011 (DOY 175199). The majority of the sampling time was spent north of $50^{\circ} \mathrm{N}$ in the Arctic biogeochemical province as defined by Longhurst (1995). Four stations in this region (ST181, ST184, ST187, ST191) were occupied for periods of $24 \mathrm{~h}$ or more, and the remainder of the data was collected underway (Fig. 1, shaded gray in Fig. 2). Station locations were selected to sample regions of elevated seawater DMS and $p \mathrm{CO}_{2}$ drawdown and/or were defined opportunistically so as to collect data during strong frontal events with intermediate to high wind speeds.

Meteorological and oceanographic measurements during the cruise are shown as time series in Fig. 2. Sea surface temperatures (SST) ranged from roughly $15^{\circ} \mathrm{C}$ in the Gulf Stream region to about $10^{\circ} \mathrm{C}$ in the high-latitude North Atlantic. Surface air temperatures were within $\pm 1-2^{\circ} \mathrm{C}$ of SST for most of the cruise, with the exception of the Gulf Stream, where SST was several degrees warmer than the overlying air. Bulk sensible heat fluxes typically ranged from -20 to $+40 \mathrm{~W} \mathrm{~m}^{-2}$. Atmospheric boundary layer stability was close to neutral (defined as $|z / L|<0.07$ ) for $>75 \%$ of the cruise. The atmosphere was consistently unstable $(z / L<-0.07)$ in the Gulf Stream (DOY 181) and during the low wind speed period on DOY 184. A stable atmosphere suppresses the size of turbulent eddies, which Yang et al. (2011) identify as potentially anomalous in their eddy covariance data. The Knorr_11 cruise encountered $z / L>0.05$ very infrequently ( $<8 \%$ of the cruise) and with no apparent bias upon the data.

The cruise track involved transit across strong gradients in chlorophyll associated with the continental shelf and the highly productive North Atlantic bloom region (Fig. 1). Chlorophyll $a$ concentrations along the ship track were extracted from $4 \mathrm{~km}$ resolution MODIS AQUA satellite ocean color images. These data ranged from 0.2 to $1.9 \mathrm{mg} \mathrm{m}^{-3}$ (Fig. 2b). A high chlorophyll region was encountered over the relatively shallow Grand Banks coastal shelf on the northward transect (DOY 180). Numerous phytoplankton blooms were encountered in the high-latitude North Atlantic. Discrete pigment samples collected in these blooms during DOY 187.8-191.0 indicate a mixture of prymnesiophytes (likely coccolithophores), diatoms and dinoflagellates (D. Repeta, personal communication, 2012).

Seawater DMS levels $\left(\mathrm{DMS}_{\mathrm{sw}}\right)$ ranged from about $2 \mathrm{nM}$ in the Gulf Stream to a high of 10.0-14.3 nM in a large algal bloom west of ST187 (DOY 188). In general, elevated DMS levels in the high-latitude North Atlantic are associated with high chlorophyll levels. However, the relationship is not simple because DMS production and consumption pathways change due to shifts in species composition and the activities of algal and bacterial populations (Stefels et al., 2007). A previous cruise in this region found high $\mathrm{DMS}_{\mathrm{sw}}$ levels in conjunction with the MODIS measurement of particulate inorganic carbon (Marandino et al., 2008), and a similar correspondence was observed during Knorr_11. Atmospheric DMS levels (DMS ${ }_{\text {air }}$ ) ranged from 64 to 1867 ppt. In general, higher atmospheric DMS levels were encountered over the highly productive high-latitude waters. However, $\mathrm{DMS}_{\text {air }}$ is also influenced by a number of other parameters, such as variability in wind speed, air mass trajectories, atmospheric oxidation rates, and boundary layer height. The surface ocean was always supersaturated with DMS, and atmospheric DMS levels were more than an order of magnitude lower than those in surface seawater. Thus, the air-sea DMS concentration difference was essentially controlled by the $\mathrm{DMS}_{\mathrm{sw}}$ concentration.

Eddy covariance DMS flux ( $\left.F_{\text {DMS }}\right)$ measurements for 10 min flux intervals are shown in Fig. 2d. DMS flux exhibits a higher degree of variability than either $\mathrm{DMS}_{\mathrm{sw}}$ or wind speed alone, as expected given that both parameters contribute to control the flux. The lowest $F_{\text {DMS }}$ were observed in the Gulf Stream on DOY 181 with low wind speed and $\mathrm{DMS}_{\mathrm{sw}}$, and the highest $F_{\mathrm{DMS}}$ were observed during 
the period of high DMS $\mathrm{Sw}_{\mathrm{sw}}$ and wind speed on DOY 188. Gas transfer coefficients were computed from the measured $F_{\text {DMS }}$ and air-sea concentration difference (Eqs. 4-6) and are shown as a time series in Fig. 2e. In general, variations in the gas transfer coefficient correlate with the mean horizontal wind speed (Spearman's $\rho=0.53, \alpha<0.01, n=1083$ ). This correlation is particularly clear during frontal passages when wind speed changed rapidly, such as the end of DOY 181 and during DOY 184. There is a notable exception near the end of the cruise, where gas transfer coefficients hardly varied during a period when wind speeds ranged from 5 to $18 \mathrm{~m} \mathrm{~s}^{-1}$ (DOY 190.1-190.3, ST191).

\subsection{Gas exchange $\left(k_{660}\right)$ vs. wind speed $\left(U_{10 n}\right)$}

The relationship between $k_{660}$ and horizontal wind speed is shown as a scatter plot (Fig. 3a). There is a positive correlation for the data set as a whole, but it is clear that the data are not normally distributed about a single linear trend line. The gas transfer coefficients exhibit the highest values at intermediate wind speeds $\left(5-10 \mathrm{~m} \mathrm{~s}^{-1}\right)$, while at higher wind speeds $\left(10-17 \mathrm{~m} \mathrm{~s}^{-1}\right)$ the gas transfer coefficients level off or even decrease. This is clearly illustrated when the data set is binaveraged by wind speed (Fig. 3b). Bin-averaged gas transfer velocities at wind speeds greater than $11 \mathrm{~m} \mathrm{~s}^{-1}$ demonstrate a marked departure from the trend observed at lower wind speeds.

Bin-averaged Knorr_11 gas transfer coefficients are compared to previously published shipboard DMS eddy covariance measurements (Fig. 3b). Bin-averaged Knorr_11 gas transfer coefficients are similar to those from previous studies for wind speeds from 0 to $11 \mathrm{~m} \mathrm{~s}^{-1}$. Only two previous studies have reported DMS flux data for wind speeds greater than $11 \mathrm{~m} \mathrm{~s}^{-1}$ : the DOGEE and Southern Ocean GasEx studies (Huebert et al., 2010). The Knorr_11 data are significantly lower than the DOGEE and Southern Ocean GasEx studies at high wind speeds.

Direct comparison of gas transfer coefficients measured under different conditions in various field programmes is complicated by the influence of sea surface temperature (Huebert et al., 2010; Yang et al., 2011). Sea surface temperature influences DMS solubility, which affects the relative importance of air-side vs. water-side resistance. A second issue is the effect of temperature on gas diffusivity, which is described by the Schmidt number $\left(S c_{\mathrm{DMS}}\right)$. The effect of temperature on solubility and $S c_{\text {DMS }}$ are accounted for in the calculation of $k_{\mathrm{w}}$ and $k_{660}$ respectively (see Methods). In addition, the bubble-driven component of gas transfer $\left(k_{\mathrm{b}}\right)$ is inversely related to gas solubility (Woolf, 1997). The temperature effect on $k_{\mathrm{b}}$ is difficult to estimate, because it requires a priori knowledge about the relative contributions of bubble and non-bubble fluxes under field conditions. Yang et al. (2011) used the COARE model to demonstrate that the uncertainty introduced by this correction is small for DMS $\left(<5 \%\right.$ at $U_{10 n}=10 \mathrm{~m} \mathrm{~s}^{-1}$ for a temperature range of $\left.5-27.2{ }^{\circ} \mathrm{C}\right)$. The $k_{\mathrm{b}}$ solubility adjustment has been applied to all eddy covariance data sets presented in Fig. $3 \mathrm{~b}$ with the exception of this study and data from the tropical and subtropical Pacific (Marandino et al., 2007, 2009).

The large spread in gas transfer coefficients and complexity of the $k$ vs. $U$ relationship argues that factors other than wind speed exert a significant control on gas transfer. In an effort to identify these factors, we subdivided the cruise data into segments: each of the four stations and the transects between them (Fig. 4a, b; Table 1). This reveals some significant differences in gas transfer over the course of the cruise. Most notably, ST184 and ST187 define a trend line with a slope $(k / U)$ roughly twice that defined by the data from ST191. As mentioned above, at ST191 the gas transfer coefficient shows evidence of leveling off or decreasing with increasing wind speed.

Data from the underway transects are concentrated primarily in the intermediate wind speed range (Fig. 4b). In the 6$12 \mathrm{~m} \mathrm{~s}^{-1}$ wind speed range the transect data have a similar lower $k / U$ bound as the station data, but a considerably wider range. Taken alone, the transect measurements give the impression of very steep wind speed dependence. More likely, the wide range of $k / U$ reflects the much larger variability in conditions (DMS $\mathrm{Dw}_{\mathrm{sw}}$, wind speed, waves) encountered during transects. To our knowledge, there are no previous eddy covariance gas flux studies comparing data from station and transect measurements.

An earlier cruise in the high-latitude North Atlantic coccolithophore bloom southwest of Iceland reported DMS gas transfer velocities that were substantially elevated relative to typical open-ocean data (Knorr_07, Marandino et al., 2008). Marandino et al. (2008) speculated that the anomaly was caused by accumulation of DMS- or DMSP-rich biological material at the sea surface, but this remains unverified. Substantially elevated gas transfer velocities were not observed during Knorr_11 although the cruise track did not extend as far north as Knorr_07, and the seawater DMS levels were generally lower.

\subsection{Transfer coefficients for momentum $\left(C_{\mathrm{D} 10}\right)$ and sensible heat $\left(C_{\mathrm{H} 10}\right)$}

Eddy covariance momentum and sensible heat fluxes were calculated from the Knorr_11 measurements using $10 \mathrm{~min}$ averaging intervals. Drag $\left(C_{\mathrm{D} 10}\right)$ and sensible heat $\left(C_{\mathrm{H} 10}\right)$ transfer coefficient values were calculated from the data following Kondo (1975). Knorr_11 $C_{\mathrm{D} 10}$ shows a general increase from approximately $1.0 \times 10^{-3}$ to $1.5 \times 10^{-3}$ as wind speeds increase from $<5 \mathrm{~m} \mathrm{~s}^{-1}$ to $20 \mathrm{~m} \mathrm{~s}^{-1}$ (Fig. 5a). The measured transfer coefficients are in reasonable agreement with those calculated using the NOAA COARE model for the Knorr_11 conditions (Fig. 5a, b). Knorr_11 $C_{\mathrm{H} 10}$ data cluster around $1 \times 10^{-3}$ with little or no wind speed dependence (Fig. 5b). NOAA COARE model heat transfer coefficients for these conditions exhibit a bias high at lower wind 

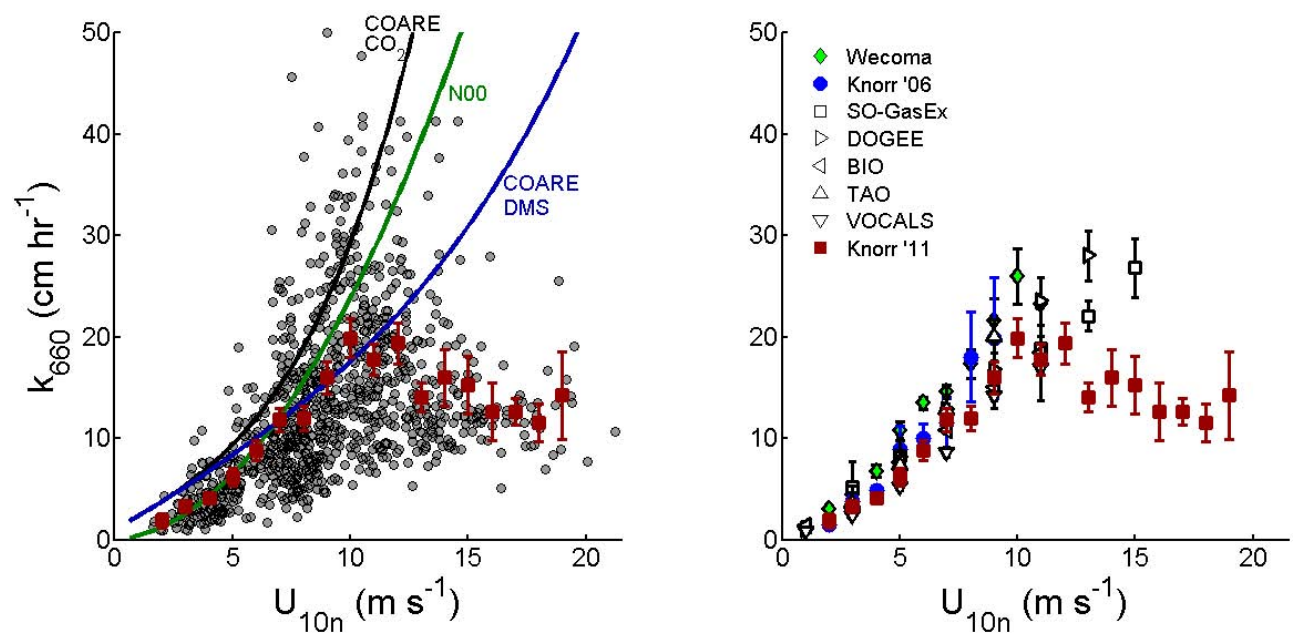

Fig. 3. Left panel: 10 min average DMS gas transfer coefficients vs. mean horizontal wind speed during the Knorr_11 cruise, expressed as $k_{660}$ and $U_{10 n}$ (see Methods). Mean $k_{660}$ values were calculated for $1 \mathrm{~m} \mathrm{~s}^{-1} U_{10 n}$ bins (closed squares, error bars represent \pm 2 std. error; minimum data points per interval $=6$ ). For reference we plot the NOAA COARE model output using the turbulent/molecular coefficient, $A=1.6$, and the bubble-mediated coefficient, $B=1.8$, for $\mathrm{CO}_{2}$ and DMS (using average Knorr_11 input parameters) and the Nightingale et al. (2000) parameterization (N00). Right panel: bin average gas transfer coefficients from this study (Knorr_11) compared with previously published DMS eddy covariance measurements: Wecoma (Marandino et al., 2007), Knorr_06 (Marandino et al., 2008), SO-GasEx (Yang et al., 2011), DOGEE (Huebert et al., 2010), BIO (Blomquist et al., 2006), TAO (Huebert et al., 2004) and VOCALS (Yang et al., 2011).
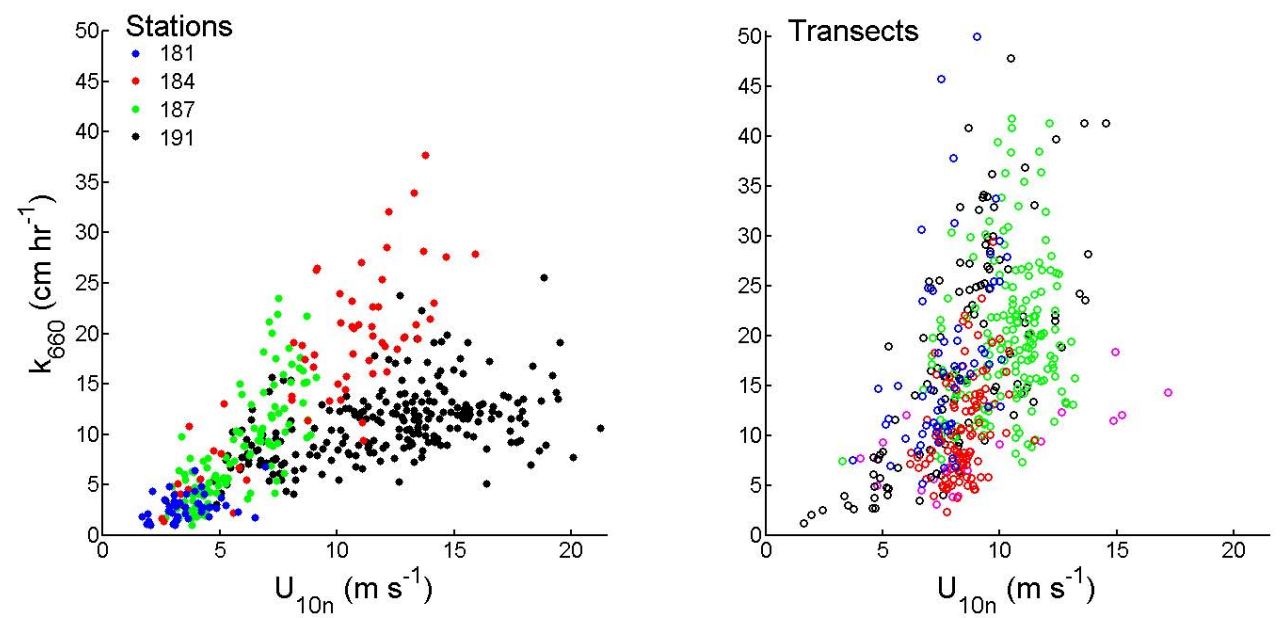

Fig. 4. Knorr_11 gas transfer coefficients plotted as a function of wind speed. The left panel shows data segregated into the individual stations as follows: stations 181 (blue), 184 (red), 187 (green) and 191 (black). The right panel shows data from underway transits segregated as follows: DOYs 179-180.8 (blue), 181.8-183.7 (red), 184.7-186.7 (green), 187.9-189.7 (black) and 193.2-193.4 (pink).

speeds and a bias low at the higher wind speeds. There is no evidence of suppression of either momentum or sensible heat transfer coefficients under the high wind speed conditions during ST191.

\subsection{Waves, whitecaps and gas transfer}

Wave spectra, wave age and significant wave height $\left(H_{\mathrm{S}}\right)$ were examined to compare the wave fields among the different stations occupied during the cruise (Fig. 6). Wave age was characterized as $U_{10 n} / C_{\mathrm{P}}$, where $C_{\mathrm{P}}$ is the speed of the waves at the peak frequency (older swell, $U_{10 n} / C_{\mathrm{P}}<1$; younger wind sea, $U_{10 n} / C_{\mathrm{P}} \geq 1$ ). The frequency of the peak in the wave spectrum was similar at all stations, occurring between 0.05 and $0.3 \mathrm{~Hz}$. Older swell was encountered during all four stations. Significant wave height $\left(H_{\mathrm{S}}\right)$ rarely exceeded $3 \mathrm{~m}$ except during ST191 (Fig. 6c). During ST191 the wave field was dominated by young waves which built rapidly from $H_{\mathrm{S}}=2$ to $5 \mathrm{~m}$ as a result of strong local winds (Fig. 6b). Even at intermediate winds $\left(8-12 \mathrm{~m} \mathrm{~s}^{-1}\right)$, consistently larger wave heights occurred at ST191 compared to the other stations. During this period of strong winds and large, 
Table 1. Average (mean) $k_{660}$ values for $U_{10 n}$ bins. Error bars represent \pm one standard error, number of data points $(n)$ is in brackets. Entire cruise data were binned into $1 \mathrm{~m} \mathrm{~s}^{-1}$ bins. Station data were binned into $2 \mathrm{~m} \mathrm{~s}^{-1}$ bins. Minimum $n$ per wind speed bin $=6$.

\begin{tabular}{|c|c|c|c|c|c|}
\hline$U_{10 n}$ Bin Average & Entire Cruise & Station 181 & Station 184 & Station 187 & Station 191 \\
\hline \multicolumn{6}{|l|}{1} \\
\hline 2 & $1.9 \pm 0.3(9)$ & $2.4 \pm 0.4(12)$ & $-(2)$ & $-(2)$ & $-(1)$ \\
\hline 3 & $3.3 \pm 0.3(36)$ & & & & \\
\hline 4 & $4.1 \pm 0.3(53)$ & $2.9 \pm 0.2(25)$ & $5.4 \pm 0.9(9)$ & $4.2 \pm 0.3(45)$ & $-(5)$ \\
\hline 5 & $6.2 \pm 0.4(53)$ & & & & \\
\hline 6 & $8.8 \pm 0.5(43)$ & $-(2)$ & $-(5)$ & $9.0 \pm 0.6(29)$ & $8.1 \pm 0.4(24)$ \\
\hline 7 & $11.9 \pm 0.6(105)$ & & & & \\
\hline 8 & $12.1 \pm 0.6(133)$ & - & $15.8 \pm 1.1(7)$ & $13.5 \pm 0.8(35)$ & $8.6 \pm 0.7(26)$ \\
\hline 9 & $16.0 \pm 0.8(113)$ & & & & \\
\hline 10 & $19.9 \pm 1.0(85)$ & - & $19.4 \pm 1.1(15)$ & $-(2)$ & $9.8 \pm 0.5(26)$ \\
\hline 11 & $17.8 \pm 0.8(95)$ & & & & \\
\hline 12 & $19.5 \pm 1.0(62)$ & - & $20.2 \pm 1.3(18)$ & & $11.7 \pm 0.5$ \\
\hline 13 & $14.2 \pm 0.7(53)$ & & & & \\
\hline 14 & $16.1 \pm 1.4(34)$ & - & $26.5 \pm 2.3(8)$ & & $12.4 \pm 0.5(56)$ \\
\hline 15 & $15.3 \pm 1.4(23)$ & & & & \\
\hline 16 & $12.7 \pm 1.4(14)$ & - & $-(1)$ & & $12.3 \pm 0.5(27)$ \\
\hline 17 & $12.6 \pm 0.6(11)$ & & & & \\
\hline 18 & $11.5 \pm 0.9$ (9) & - & & & $12.2 \pm 1.0$ \\
\hline 19 & $14.2 \pm 2.2(7)$ & & & & \\
\hline 20 & - & - & & & $-(5)$ \\
\hline
\end{tabular}
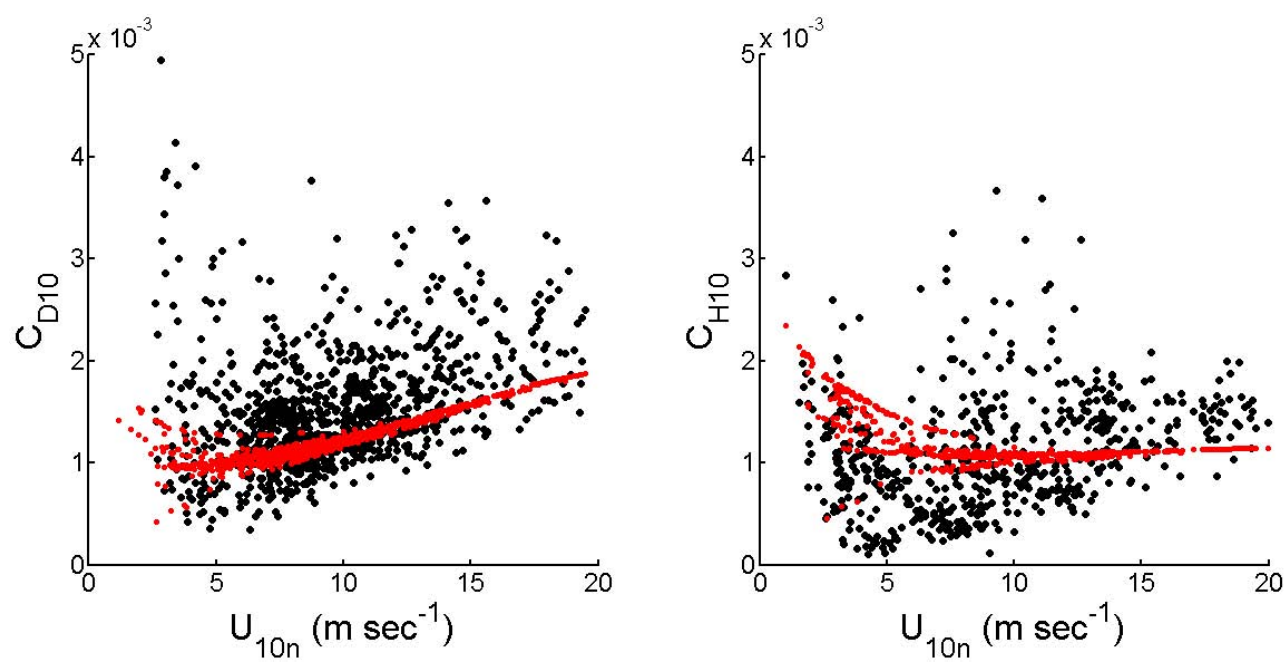

Fig. 5. Momentum (left) and sensible heat (right) transfer coefficients during Knorr_11. Black: eddy covariance measurements for 10 min intervals. Red: transfer coefficients calculated using the NOAA COARE model (Fairall et al., 2003) for the environmental conditions encountered during Knorr_11.

wind-driven waves, $k_{660}$ values (Fig. 6d) were anomalously low whenever $H_{\mathrm{S}}$ exceeded $3 \mathrm{~m}$ (Fig. 7a).

Whitecap area coverage varied during the cruise from below detection to a maximum of about $5 \%$. Whitecaps exceeded $2 \%$ on two occasions during the cruise. These occurred during stations 184 and 191, associated with wind speeds exceeding $15 \mathrm{~m} \mathrm{~s}^{-1}$ and with young, wind-driven seas. Although the two stations exhibited similar whitecap coverage during their peak winds, significant wave height was nearly two-fold larger at station 191 ( $5 \mathrm{~m}$ maximum) than at station 184 ( $3 \mathrm{~m}$ maximum). The anomalous low DMS gas transfer coefficients observed during station 191 may therefore be more directly linked to the appearance of large waves than to the onset of whitecaps (Fig. 7b). 


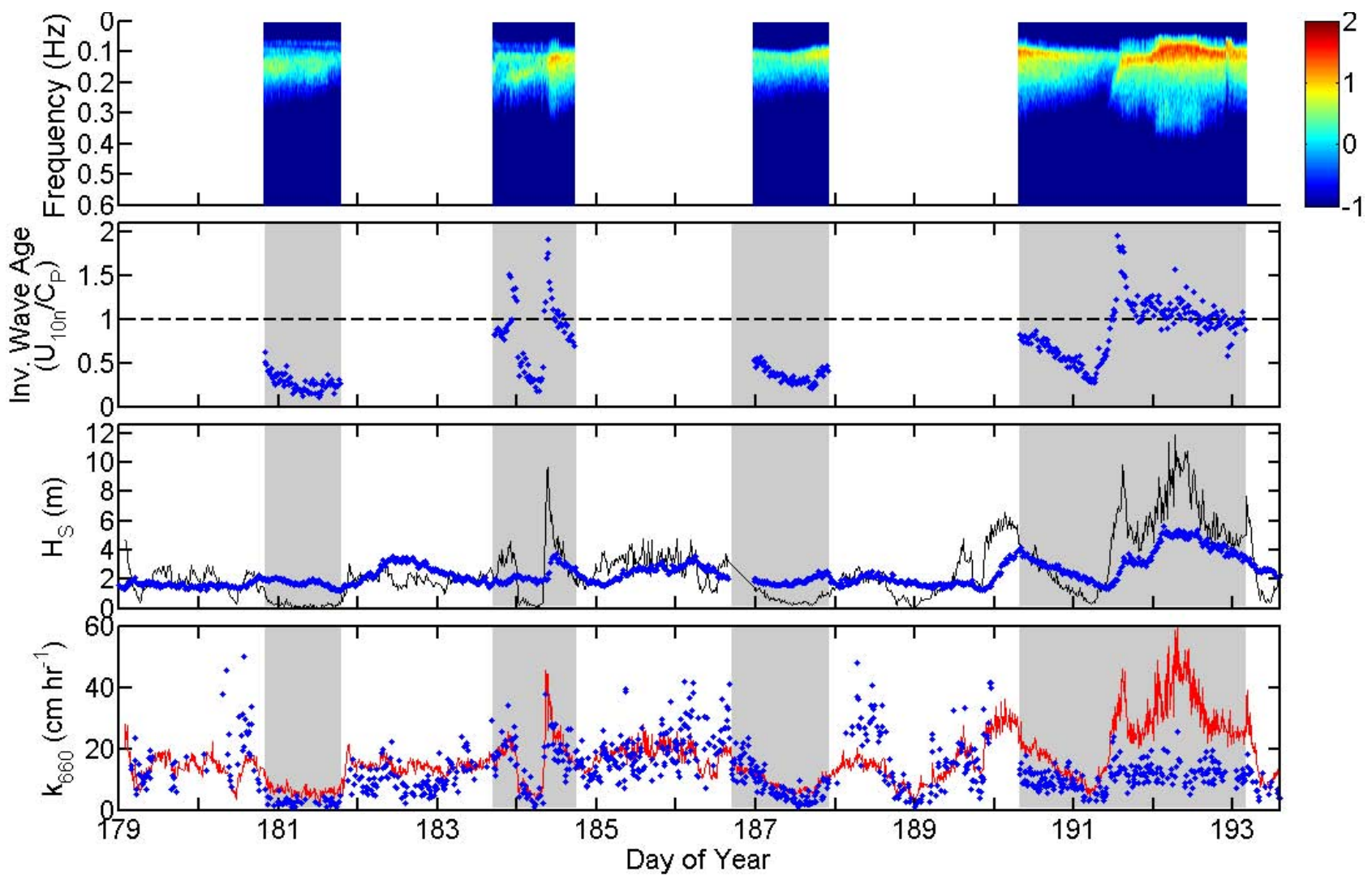

Fig. 6. Wave properties measured during Knorr_11. From top: (a) wave spectra (data only reported on station); (b) inverse wave age defined as $U_{10 n} / C_{\mathrm{p}}$; (c) significant wave height ( $H_{\mathrm{S}}$, blue dots), and the Alves et al. (2003) empirical parameterization of $H_{\mathrm{S}}$ for fully developed seas: $H_{\mathrm{S}}=0.025 \cdot U_{10 n}^{2.01}$ (black line); and (d) gas transfer coefficient for DMS (as $k_{660}$, blue dots) with NOAA COARE DMS model (red line).

\section{Discussion}

The data from Knorr_11 confirm the linear dependence of $k$ vs. $U$ at low to intermediate wind speeds observed in previous eddy covariance studies. This wind speed dependence appears to weaken at higher wind speeds in the presence of large waves. The data show evidence of spatial/temporal variability in the $k$ vs. $U$ relationship, suggesting that gas transfer in the North Atlantic is not well described by a single monotonic relationship between $k$ and mean wind speed $\left(U_{10 n}\right)$. Most gas transfer parameterizations are based solely on the relationship between $k$ and mean wind speed $\left(U_{10 n}\right)$, but it is widely recognized that gas transfer rates reflect a number of different processes that influence near-surface turbulence and mixing (Wanninkhof et al., 2009). We speculate that variations in surfactants and/or wind-wave interactions are likely causes of variability in $k$ vs. $U$ in this study.

Laboratory studies have shown that gas transfer is related to the presence and microbreaking of small-scale waves (Ocampo-Torres et al., 1994; Jähne et al., 1987; Zappa et al., 2004). Small-scale wave properties are primarily winddriven, but they can also be modulated by the presence of long waves (Donelan et al., 2010). Long waves and short waves are coupled through both hydrodynamic and windrelated processes. This coupling has a significant impact on air-sea transfer of momentum and it must also influence gas transfer. There has been little study of this phenomenon with regard to gas transfer, although a recent windwave tank study showed suppression of DMS gas transfer induced by superimposing mechanically generated waves on a wind-generated wave field (Rhee et al., 2007). The presence of long waves may affect gas transfer of different gases to different extents. For example, gas transfer of $\mathrm{CO}_{2}$ is highly sensitive to large wave breaking and bubble formation. By contrast, bubble-mediated exchange of the more soluble DMS is minor, and DMS is likely more strongly influenced by processes that affect small-scale interfacial turbulence (Woolf, 1997; Blomquist et al., 2006).

It is interesting that $k_{660}$ showed evidence of suppression at high wind speeds during Knorr_11 at ST191 (Fig. 4), while the transfer coefficients for sensible heat did not (Fig. 5b). Sensible heat transfer is entirely air-side controlled. This difference in behaviour indicates that air-side turbulence increased strongly with wind speed, while the interfacial stress 

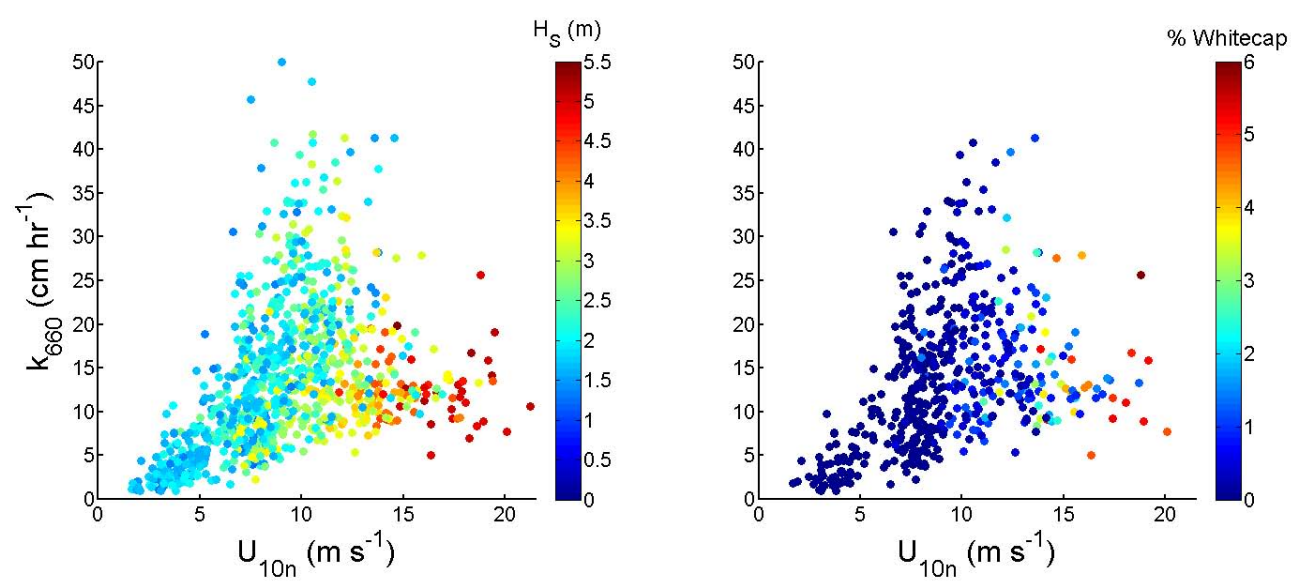

Fig. 7. Knorr_11 gas transfer coefficients plotted as a function of wind speed, with symbol color indicating significant wave height (a) and $\%$ whitecap area coverage (b).

controlling DMS flux did not. Laboratory studies have suggested that air flow separation at the crests of large waves can effectively shield the troughs from wind stress (Reul et al., 1999, 2008; Veron et al., 2007). This could reduce surface stress at the sea surface and increase water-side resistance (thereby reducing $k_{660}$ ). In this scenario, the sensible heat results suggest that sufficient atmospheric turbulence must be associated with the flow separation process to maintain strong atmospheric mixing even while surface stress is reduced.

The modulation of surface ocean turbulence by large gravity waves has been incorporated into some physical processbased surface renewal and energy dissipation gas transfer models (Soloviev et al., 2007; Soloviev, 2007; Soloviev and Schlussel, 1994). Soloviev (2007) used the dimensionless Keulegan number to scale the relationship between tangential and total surface stress:

$K e=u_{*}^{3} / g \cdot v$,

where $u_{*}$ is water-side friction velocity, $v$ is seawater viscosity, and $g$ is gravity (Csanady, 1978). In this model, the relationship between total surface wind stress and tangential surface wind stress is given by

$\tau_{\text {tangential }}=\frac{\tau_{\text {total }}}{1+K e / K e_{\mathrm{CR}}}$,

where $K e_{\mathrm{CR}}$ is based on the wave breaking parameterization of Zhao and Toba (2001). This leads to a formulation that links $K e_{\mathrm{CR}}$ (and interfacial gas transfer) to wave age, peak frequency, or significant wave height (Soloviev et al., 2007). The same wave breaking parameterization has also been used to describe the sea state dependence of gas transfer by bubbles (Woolf, 2005; Soloviev et al., 2007; Zhao et al., 2003). Simulations of the conditions during the Knorr_11 cruise illustrate the potential sensitivity of gas transfer to the pres- ence of long waves and to wave age (Fig. 8). Interfacial transfer was parameterized using the Soloviev (2007) model (see Supplement for equations).

The bubble-mediated transfer term is a small contribution to $k_{\mathrm{DMS}}$, so the sensitivity of gas transfer to wave age results primarily from changes in interfacial transfer.

Organic surfactants on the sea surface offer an alternate explanation for wide variations in $k$ vs. wind speed. Surfactants modify the viscoelastic properties of seawater and suppress surface turbulence. This, in turn, suppresses the formation of small-scale waves and reduces gas transfer (Salter et al., 2011; Frew et al., 1990). Marine surfactants are related to the abundance and chemistry of biologically generated organic matter in the water column and to wave breaking, as surfactants are transported to the sea surface via bubbles. It is believed that surfactants can influence gas transfer at all wind speeds, both by influencing interfacial transfer and by altering bubble surface properties (Wurl et al., 2011). The effect of surfactants has not yet been incorporated into gas transfer models, presumably because of the lack of information about their distribution and properties. There were no measurements of surfactant properties on Knorr_11, and thus we cannot quantify their effect upon gas exchange during this study.

\section{Conclusions}

The data from Knorr_11 demonstrate that eddy covariance DMS flux measurements, in conjunction with continuous seawater measurements, have the potential to capture variability in air-sea fluxes on sufficiently short timescales to resolve underlying processes if the relevant physical measurements are available. The relatively high solubility of DMS makes the flux sensitive to the interfacial component of gas transfer and relatively insensitive to the bubble-mediated component (Blomquist et al., 2006). For this reason DMS 


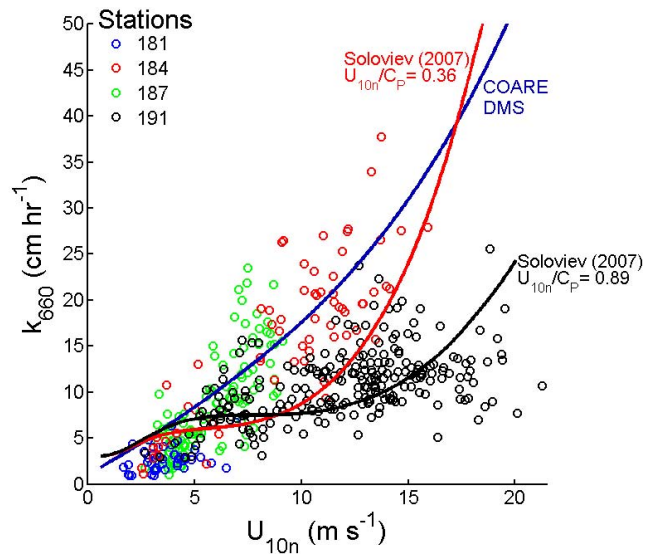

Fig. 8. Measured and modelled DMS gas transfer coefficients. Symbols: Knorr_11 station data. Curves: model simulations from the COARE 3.1 DMS parameterization which does not include waves (blue) and the Soloviev (2007) parameterization using mean inverse wave age from station $184\left(U_{10 n} / C_{\mathrm{P}}=0.36\right)$ and station $191\left(U_{10 n} / C_{\mathrm{P}}=0.89\right)$.

fluxes are a useful tool for understanding near-surface turbulence and the factors that control interfacial exchange.

The weak dependence of $k_{\mathrm{DMS}}$ vs. $U$ at high wind speeds observed during this cruise was unexpected. There is one previous report of anomalously low $k_{\mathrm{DMS}}$ values at high wind speeds for a limited portion of the Southern Ocean GasEx cruise (Yang et al., 2011; Vlahos et al., 2010). Vlahos et al. (2010) explained this phenomenon in terms of a reduction in effective solubility due to surface activity on bubbles, but this explanation appears unlikely given the small areal coverage of whitecaps observed during Knorr_11. The weakened wind speed dependence on Knorr_11 was associated with the presence of large wind-driven waves, but was less directly linked to the onset of wave breaking and whitecap formation. We offer wind-wave coupling as an alternative explanation. However, we stress the need for additional field measurements to validate our observations and confirm that low $k_{\text {DMS }}$ at high wind speeds is in fact a real environmental phenomenon and not an experimental artefact of unknown origin. Future studies should focus on simultaneous measurement of gas transfer, directional wave fields, surface tension, surfactant properties and turbulence.

\section{Supplementary material related to this article is available online at http://www.atmos-chem-phys.net/13/ 11073/2013/acp-13-11073-2013-supplement.pdf.}

Acknowledgements. The authors thank the Woods Hole Marine Department and the Captain and crew of the R/V Knorr for their assistance in carrying out this cruise. We also thank Dan Repeta (WHOI) for pigment analysis and David Woolf, Chris Zappa and Mingxi Yang for insightful discussion. This research was supported by the NSF Atmospheric Chemistry Program (grant nos. 0851068, 0851472, 0851407 and 1143709) and is a contribution to US SOLAS. Wave sensor construction and the work of K. Christensen were supported by the Research Council of Norway (grant no. 196438, BIOWAVE). B. Ward acknowledges support from Science Foundation Ireland under grant 08/US/I1455 and from the FP7 Marie Curie Reintegration programme under grant 224776.

Edited by: T. Bertram

\section{References}

Alves, J., Banner, M. L., and Young, I. R.: Revisiting the PiersonMoskowitz asymptotic limits for fully developed wind waves, J. Phys. Oceanogr., 33, 1301-1323, 2003.

Bandy, A. R., Thornton, D. C., Tu, F. H., Blomquist, B. W., Nadler, W., Mitchell, G. M., and Lenschow, D. H.: Determination of the vertical flux of dimethyl sulfide by eddy correlation and atmospheric pressure ionization mass spectrometry (APIMS), J. Geophys. Res.-Atmos., 107, 4743, doi:10.1029/2002jd002472, 2002.

Bange, H. W., Bell, T. G., Cornejo, M., Freing, A., Uher, G., UpstillGoddard, R. C., and Zhang, G.: MEMENTO: A proposal to develop a database of marine nitrous oxide and methane measurements, Environ. Chem., 6, 195-197, 2009.

Blomquist, B. W., Fairall, C. W., Huebert, B. J., Kieber, D. J., and Westby, G. R.: DMS sea-air transfer velocity: Direct measurements by eddy covariance and parameterization based on the NOAA/COARE gas transfer model, Geophys. Res. Lett., 33, L07601, doi:10.1029/2006g1025735, 2006.

Blomquist, B. W., Huebert, B. J., Fairall, C. W., and Faloona, I. C.: Determining the sea-air flux of dimethylsulfide by eddy correlation using mass spectrometry, Atmos. Meas. Tech., 3, 1-20, doi:10.5194/amt-3-1-2010, 2010.

Broecker, W. S., Peng, T. H., Ostlund, G., and Stuiver, M.: The distribution of bomb radiocarbon in the ocean, J. Geophys. Res.Oceans, 90, 6953-6970, 1985.

Butler, J. H., Bell, T. G., Hall, B. D., Quack, B., Carpenter, L. J., and Williams, J.: Technical Note: Ensuring consistent, global measurements of very short-lived halocarbon gases in the ocean and atmosphere, Atmos. Chem. Phys., 10, 327-330, doi:10.5194/acp-10-327-2010, 2010.

Callaghan, A. H. and White, M.: Automated processing of sea surface images for the determination of whitecap coverage, J. Atmos. Ocean. Tech., 26, 383-394, doi:10.1175/2008jtecho634.1, 2009.

Christensen, K. H., Röhrs, R., Ward, B., Drivdal, M., and Broström, G.: Surface wave measurements using a ship mounted ultrasonic altimeter, ASLO Ocean Sciences Meeting, Salt Lake City, USA, 2012 ,

Csanady, G. T.: Turbulent interface layers, J. Geophys. Res., 83, 2329-2342, 1978

Dacey, J. W. H., Wakeham, S. G., and Howes, B. L.: Henry's law constants for dimethylsulfide in fresh water and seawater, Geophys. Res. Lett., 11, 991-994, 1984. 
Donelan, M. A., Haus, B. K., Plant, W. J., and Troianowski, O.: Modulation of short wind waves by long waves, J. Geophys. Res.-Oceans, 115, C10003, doi:10.1029/2009jc005794, 2010.

Edson, J. B., Hinton, A. A., Prada, K. E., Hare, J. E., and Fairall, C. W.: Direct covariance flux estimates from mobile platforms at sea, J. Atmos. Ocean. Tech., 15, 547-562, doi:10.1175/15200426(1998)015<0547:DCFEFM>2.0.CO;2, 1998.

Elliott, S.: Dependence of DMS global sea-air flux distribution on transfer velocity and concentration field type, J. Geophys. Res.Biogeosci., 114, G02001, doi:10.1029/2008JG000710, 2009.

Fairall, C. W., Bradley, E. F., Rogers, D. P., Edson, J. B., and Young, G. S.: Bulk parameterization of air-sea fluxes for Tropical OceanGlobal Atmosphere Coupled-Ocean Atmosphere Response Experiment, J. Geophys. Res.-Oceans, 101, 3747-3764, 1996.

Fairall, C. W., Yang, M., Bariteau, L., Edson, J. B., Helmig, D., McGillis, W., Pezoa, S., Hare, J. E., Huebert, B., and Blomquist, B.: Implementation of the Coupled OceanAtmosphere Response Experiment flux algorithm with $\mathrm{CO}_{2}$, dimethyl sulfide, and $\mathrm{O}_{3}$, J. Geophys. Res.-Oceans, 116, C00F09, doi:10.1029/2010jc006884, 2011.

Frew, N. M., Goldman, J. C., Dennett, M. R., and Johnson, A. S.: Impact of phytoplankton-generated surfactants on air-sea gas exchange, J. Geophys. Res.-Oceans, 95, 3337-3352, 1990.

García-Nava, H., Ocampo-Torres, F. J., Osuna, P., and Donelan, M. A.: Wind stress in the presence of swell under moderate to strong wind conditions, J. Geophys. Res.-Oceans, 114, C00J11, doi:10.1029/2009JC005389, 2009.

García-Nava, H., Ocampo-Torres, F. J., Hwang, P. A., and Osuna, P.: Reduction of wind stress due to swell at high wind conditions, J. Geophys. Res.-Oceans, 117, C12008, doi:10.1029/2011JC007833, 2012.

Hare, J. E., Fairall, C. W., McGillis, W. R., Edson, J. B., Ward, B., and Wanninkhof, R.: Evaluation of the National Oceanic and Atmospheric Administration/Coupled-Ocean Atmospheric Response Experiment (NOAA/COARE) air-sea gas transfer parameterization using GasEx data, J. Geophys. Res.-Oceans, 109, C08S11, doi:10.1029/2003JC001831, 2004.

Harman-Fetcho, J. A., McConnell, L. L., Rice, C. P., and Baker, J. E.: Wet deposition and air-water gas exchange of currently used pesticides to a subestuary of the Chesapeake Bay, Environ. Sci. Technol., 34, 1462-1468, doi:10.1021/Es9909551, 2000.

Ho, D. T., Law, C. S., Smith, M. J., Schlosser, P., Harvey, M., and Hill, P.: Measurements of air-sea gas exchange at high wind speeds in the Southern Ocean: Implications for global parameterizations, Geophys. Res. Lett., 33, L16611, doi:10.1029/2006GL026817, 2006.

Huebert, B. J., Blomquist, B. W., Hare, J. E., Fairall, C. W., Johnson, J. E., and Bates, T. S.: Measurement of the sea-air DMS flux and transfer velocity using eddy correlation, Geophys. Res. Lett., 31, L23113, doi:10.1029/2004GL021567, 2004.

Huebert, B. J., Blomquist, B. W., Yang, M. X., Archer, S. D., Nightingale, P. D., Yelland, M. J., Stephens, J., Pascal, R. W., and Moat, B. I.: Linearity of DMS transfer coefficient with both friction velocity and wind speed in the moderate wind speed range, Geophys. Res. Lett., 37, L01605, doi:10.1029/2009g1041203, 2010.

Jähne, B., Munnich, K. O., Bosinger, R., Dutzi, A., Huber, W., and Libner, P.: On the parameters influencing air-water gas-exchange, J. Geophys. Res.-Oceans, 92, 1937-1949, 1987.
Johnson, M. T.: A numerical scheme to calculate temperature and salinity dependent air-water transfer velocities for any gas, Ocean Sci., 6, 913-932, doi:10.5194/os-6-913-2010, 2010.

Johnson, M. T., Liss, P. S., Bell, T. G., Lesworth, T. J., Baker, A. R., Hind, A. J., Jickells, T. D., Biswas, K. F., Woodward, E. M. S., and Gibb, S. W.: Field observations of the ocean-atmosphere exchange of ammonia: Fundamental importance of temperature as revealed by a comparison of high and low latitudes, Global Biogeochem. Cy., 22, GB1019, doi:10.1029/2007GB003039, 2008.

Juranek, L. W., Hamme, R. C., Kaiser, J., Wanninkhof, R., and Quay, P. D.: Evidence of $\mathrm{O}_{2}$ consumption in underway seawater lines: Implications for air-sea $\mathrm{O}_{2}$ and $\mathrm{CO}_{2}$ fluxes, Geophys. Res. Lett., 37, L01601, doi:10.1029/2009GL040423, 2010.

Kondo, J.: Air-sea bulk transfer coefficients in diabatic conditions, Bound.-Lay. Meteorol., 9, 91-112, 1975.

Lana, A., Bell, T. G., Simó, R., Vallina, S. M., Ballabrera-Poy, J., Kettle, A. J., Dachs, J., Bopp, L., Saltzman, E. S., Stefels, J., Johnson, J. E., and Liss, P. S.: An updated climatology of surface dimethylsulfide concentrations and emission fluxes in the global ocean, Global Biogeochem. Cy., 25, GB1004, doi:10.1029/2010GB003850, 2011.

Lenschow, D. H. and Raupach, M. R.: The attenuation of fluctuations in scalar concentrations through sampling tubes, J. Geophys. Res.-Atmos., 96, 15259-15268, doi:10.1029/91jd01437, 1991.

Liss, P. S. and Merlivat, L.: Air-sea gas exchange rates: introduction and synthesis, in: The role of air-sea exchange in geochemical cycling, edited by: Buatmenard, P., Reidel, 113-127, 1986.

Liss, P. S. and Slater, P. G.: Flux of gases across the air-sea interface, Nature, 247, 181-184, 1974.

Longhurst, A.: Seasonal cycles of pelagic production and consumption, Prog. Oceanogr., 36, 77-167, 1995.

Marandino, C. A., De Bruyn, W. J., Miller, S. D., and Saltzman, E. S.: Eddy correlation measurements of the air/sea flux of dimethylsulfide over the North Pacific Ocean, J. Geophys. Res.Atmos., 112, D03301, doi:10.1029/2006JD007293, 2007.

Marandino, C. A., De Bruyn, W. J., Miller, S. D., and Saltzman, E. S.: DMS air/sea flux and gas transfer coefficients from the North Atlantic summertime coccolithophore bloom, Geophys. Res. Lett., 35, L23812, doi:10.1029/2006JD007293, 2008.

Marandino, C. A., De Bruyn, W. J., Miller, S. D., and Saltzman, E. S.: Open ocean DMS air/sea fluxes over the eastern South Pacific Ocean, Atmos. Chem. Phys., 9, 345-356, doi:10.5194/acp9-345-2009, 2009.

Massman, W. J.: A simple method for estimating frequency response corrections for eddy covariance systems, Agr. Forest Meteorol., 104, 185-198, doi:10.1016/S0168-1923(00)00164-7, 2000.

McGillis, W. R., Dacey, J. W. H., Frew, N. M., Bock, E. J., and Nelson, R. K.: Water-air flux of dimethylsulfide, J. Geophys. Res.Oceans, 105, 1187-1193, 2000.

McGillis, W. R., Edson, J. B., Hare, J. E., and Fairall, C. W.: Direct covariance air-sea $\mathrm{CO}_{2}$ fluxes, J. Geophys. Res.-Oceans, 106, 16729-16745, 2001.

McGillis, W. R., Edson, J. B., Zappa, C. J., Ware, J. D., McKenna, S. P., Terray, E. A., Hare, J. E., Fairall, C. W., Drennan, W., Donelan, M., DeGrandpre, M. D., Wanninkhof, R., and Feely, R. A.: Air-sea $\mathrm{CO}_{2}$ exchange in the equatorial Pacific, J. Geophys. Res.-Oceans, 109, C08S02, doi:10.1029/2003JC002256, 2004. 
Miller, S. D., Hristov, T. S., Edson, J. B., and Friehe, C. A.: Platform motion effects on measurements of turbulence and air-sea exchange over the open ocean, J. Atmos. Ocean. Tech., 25, 16831694, 2008.

Miller, S. D., Marandino, C., and Saltzman, E. S.: Ship-based measurement of air-sea $\mathrm{CO}_{2}$ exchange by eddy covariance, J. Geophys. Res.-Atmos., 115, D02304, doi:10.1029/2009JD012193, 2010.

Nightingale, P. D., Malin, G., Law, C. S., Watson, A. J., Liss, P. S., Liddicoat, M. I., Boutin, J., and Upstill-Goddard, R. C.: In situ evaluation of air-sea gas exchange parameterizations using novel conservative and volatile tracers, Global Biogeochem. Cy., 14, 373-387, 2000.

Ocampo-Torres, F. J., Donelan, M. A., Merzi, N., and Jia, F.: Laboratory measurements of mass transfer of carbon dioxide and water vapor for smooth and rough flow conditions, Tellus B, 46, 16-32, doi:10.1034/j.1600-0889.1994.00002.x, 1994.

Pedreros, R., Dardier, G., Dupuis, H., Graber, H. C., Drennan, W. M., Weill, A., Guerin, C., and Nacass, P.: Momentum and heat fluxes via the eddy correlation method on the R/V L'Atalante and an ASIS buoy, J. Geophys. Res.-Oceans, 108, 3339, doi:10.1029/2002JC001449, 2003.

Reul, N., Branger, H., and Giovanangeli, J. P.: Air flow separation over unsteady breaking waves, Phys. Fluids, 11, 1959-1961, 1999.

Reul, N., Branger, H., and Giovanangeli, J.-P.: Air flow structure over short-gravity breaking water waves, Bound. Lay. Meteorol., 126, 477-505, 2008.

Rhee, T. S., Nightingale, P. D., Woolf, D. K., Caulliez, G., Bowyer, P., and Andreae, M. O.: Influence of energetic wind and waves on gas transfer in a large wind-wave tunnel facility, J. Geophys. Res.-Oceans, 112, C05027, doi:10.1029/2002JC001449, 2007.

Rutgersson, A., Smedman, A.-S., and Sahlée, E.: Including mixed layer convection when determining air-sea $\mathrm{CO}_{2}$ transfer velocity, in: Gas transfer at water surfaces 2010, edited by: Komori, S., McGillis, W., and Kurose, R., Kyoto University Press, Kyoto, Japan, 2011.

Sabine, C. L., Feely, R. A., Gruber, N., Key, R. M., Lee, K., Bullister, J. L., Wanninkhof, R., Wong, C. S., Wallace, D. W. R., Tilbrook, B., Millero, F. J., Peng, T. H., Kozyr, A., Ono, T., and Rios, A. F.: The oceanic sink for anthropogenic $\mathrm{CO}_{2}$, Science, 305, 367-371, doi:10.1126/science.1097403, 2004.

Salter, M. E., Upstill-Goddard, R. C., Nightingale, P. D., Archer, S. D., Blomquist, B., Ho, D. T., Huebert, B., Schlosser, P., and Yang, M.: Impact of an artificial surfactant release on air-sea gas fluxes during Deep Ocean Gas Exchange Experiment II, J. Geophys. Res.-Oceans, 116, C11016, doi:10.1029/2011JC007023, 2011.

Saltzman, E. S., King, D. B., Holmen, K., and Leck, C.: Experimental determination of the diffusion coefficient of dimethylsulfide in water, J. Geophys. Res.-Oceans, 98, 16481-16486, 1993.

Saltzman, E. S., De Bruyn, W. J., Lawler, M. J., Marandino, C. A., and McCormick, C. A.: A chemical ionization mass spectrometer for continuous underway shipboard analysis of dimethylsulfide in near-surface seawater, Ocean Sci., 5, 537-546, doi:10.5194/os-5-537-2009, 2009.

Savelyev, I. B., Maxeiner, E., and Chalikov, D.: Turbulence production by nonbreaking waves: Laboratory and numer- ical simulations, J. Geophys. Res.-Oceans, 117, C00J13, doi:10.1029/2012jc007928, 2012.

Schnieders, J., Garbe, C. S., Peirson, W. L., Smith, G. B., and Zappa, C. J.: Analyzing the footprints of near-surface aqueous turbulence: An image processing-based approach, J. Geophys. Res.-Oceans, 118, 1272-1286, doi:10.1002/Jgrc.20102, 2013.

Smith, M. J., Ho, D. T., Law, C. S., McGregor, J., Popinet, S., and Schlosser, P.: Uncertainties in gas exchange parameterization during the SAGE dual-tracer experiment, Deep-Sea Res. Pr. II, 58, 869-881, 2011.

Soerensen, A. L., Sunderland, E. M., Holmes, C. D., Jacob, D. J., Yantosca, R. M., Skov, H., Christensen, J. H., Strode, S. A., and Mason, R. P.: An improved global model for air-sea exchange of mercury: High concentrations over the North Atlantic, Environ. Sci. Technol., 44, 8574-8580, 2010.

Soloviev, A. V., Donelan, M., Graber, H., Haus, B., and Schlüssel, P.: An approach to estimation of near-surface turbulence and $\mathrm{CO}_{2}$ transfer velocity from remote sensing data, J. Marine Syst., 66, 182-194, doi:10.1016/j.jmarsys.2006.03.023, 2007.

Soloviev, A. V.: Coupled renewal model of ocean viscous sublayer, thermal skin effect and interfacial gas transfer velocity, J. Marine Syst., 66, 19-27, doi:10.1016/j.jmarsys.2006.03.024, 2007.

Soloviev, A. X. and Schlussel, P.: Parameterization of the cool skin of the ocean and of the air ocean gas transfer on the basis of modeling surface renewal, J. Phys. Oceanogr., 24, 1339-1346, doi:10.1175/1520-0485(1994)024<1339:potcso>2.0.co;2, 1994.

Stefels, J., Steinke, M., Turner, S., Malin, G., and Belviso, S.: Environmental constraints on the production and removal of the climatically active gas dimethylsulphide (DMS) and implications for ecosystem modelling, Biogeochemistry, 83, 245-275, 2007.

Stramma, L., Johnson, G. C., Sprintall, J., and Mohrholz, V.: Expanding oxygen-minimum zones in the tropical oceans, Science, 320, 655-658, 2008.

Sweeney, C., Gloor, E., Jacobson, A. R., Key, R. M., McKinley, G., Sarmiento, J. L., and Wanninkhof, R.: Constraining global air-sea gas exchange for $\mathrm{CO}_{2}$ with recent bomb ${ }^{14} \mathrm{C}$ measurements, Global Biogeochem. Cy., 21, GB2015, doi:10.1029/2006GB002784, 2007.

Veron, F., Saxena, G., and Misra, S. K.: Measurements of the viscous tangential stress in the airflow above wind waves, Geophys. Res. Lett., 34, L19603, doi:10.1029/2007g1031242, 2007.

Vlahos, P., Monahan, E. C., Huebert, B. J., and Edson, J. B.: Winddependence of DMS transfer velocity: Comparison of model with recent southern ocean observations, in: Gas Transfer at Water Surfaces 2010, edited by: Komori, S., McGillis, W., and Kurose, R., Kyoto University Press, Kyoto, 313-321, 2010.

Wanninkhof, R.: Relationship between wind speed and gas exchange over the ocean, J. Geophys. Res.-Oceans, 97, 7373-7382, 1992.

Wanninkhof, R. and McGillis, W. R.: A cubic relationship between air-sea $\mathrm{CO}_{2}$ exchange and wind speed, Geophys. Res. Lett., 26, 1889-1892, 1999.

Wanninkhof, R., Asher, W. E., Ho, D. T., Sweeney, C., and McGillis, W. R.: Advances in quantifying air-sea gas exchange and environmental forcing, Annu. Rev. Mar. Sci., 1, 213-244, doi:10.1146/annurev.marine.010908.163742, 2009.

Watson, A. J., Upstill-Goddard, R. C., and Liss, P. S.: Air-sea gas exchange in rough and stormy seas measured by a dual-tracer technique, Nature, 349, 145-147, 1991. 
Webb, E. K., Pearman, G. I., and Leuning, R.: Correction of flux measurements for density effects due to heat and water vapor transfer, Q. J. Roy. Meteorol. Soc., 106, 85-100, 1980.

Woolf, D. K.: Bubbles and their role in gas exchange, in: The Sea Surface and Global Change, edited by: Liss, P. S., and Duce, R. A., Cambridge University Press, Cambridge, 173-205, 1997.

Woolf, D. K.: Parametrization of gas transfer velocities and seastate-dependent wave breaking, Tellus B, 57, 87-94, 2005.

Wurl, O., Wurl, E., Miller, L., Johnson, K., and Vagle, S.: Formation and global distribution of sea-surface microlayers, Biogeosciences, 8, 121-135, doi:10.5194/bg-8-121-2011, 2011.

Yang, M., Blomquist, B. W., Fairall, C. W., Archer, S. D., and Huebert, B. J.: Air-sea exchange of dimethylsulfide in the Southern Ocean: Measurements from SO GasEx compared to temperate and tropical regions, J. Geophys. Res.-Oceans, 116, C00F05, doi:10.1029/2010jc006526, 2011.
Zappa, C. J., Asher, W. E., Jessup, A. T., Klinke, J., and Long, S. R.: Microbreaking and the enhancement of airwater transfer velocity, J. Geophys. Res.-Oceans, 109, C08S16, doi:10.1029/2003JC001897, 2004.

Zhao, D. and Toba, Y.: Dependence of whitecap coverage on wind and wind-wave properties, J. Ocean, 57, 603-616, 2001.

Zhao, D., Toba, Y., Suzuki, Y., and Komori, S.: Effect of wind waves on air-sea gas exchange: proposal of an overall $\mathrm{CO}_{2}$ transfer velocity formula as a function of breaking-wave parameter, Tellus B, 55, 478-487, doi:10.1034/j.1600-0889.2003.00055.x, 2003. 